\title{
nombalina
}

(8)

"São Paulo é a cabeça da nação": historiografia regional e História nacional no Brasil republicano
Autor(es):
Motta, Marly
Publicado por: Imprensa da Universidade de Coimbra
URL
persistente:
URI:http://hdl.handle.net/10316.2/38583
DOI:
DOI:http://dx.doi.org/10.14195/978-989-26-0646-0_12
Accessed : $\quad$ 26-Apr-2023 15:15:32

A navegação consulta e descarregamento dos títulos inseridos nas Bibliotecas Digitais UC Digitalis, UC Pombalina e UC Impactum, pressupõem a aceitação plena e sem reservas dos Termos e Condições de Uso destas Bibliotecas Digitais, disponíveis em https://digitalis.uc.pt/pt-pt/termos.

Conforme exposto nos referidos Termos e Condições de Uso, o descarregamento de títulos de acesso restrito requer uma licença válida de autorização devendo o utilizador aceder ao(s) documento(s) a partir de um endereço de IP da instituição detentora da supramencionada licença.

Ao utilizador é apenas permitido o descarregamento para uso pessoal, pelo que o emprego do(s) título(s) descarregado(s) para outro fim, designadamente comercial, carece de autorização do respetivo autor ou editor da obra.

Na medida em que todas as obras da UC Digitalis se encontram protegidas pelo Código do Direito de Autor e Direitos Conexos e demais legislação aplicável, toda a cópia, parcial ou total, deste documento, nos casos em que é legalmente admitida, deverá conter ou fazer-se acompanhar por este aviso.

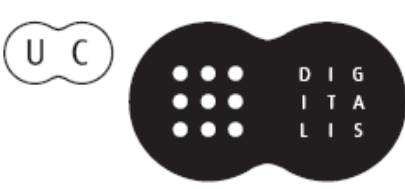




\section{“SÃo PAULO É A CABEÇA DA NAÇÃo" \\ - HISTORIOGRAFIA REGIONAL E HISTÓRIA NACIONAL NO BRASIL REPUBLICANO}

MARLY MOTTA

Um dilema impõe-se: ou essa província [São Paulo] assume decisiva preponderância no governo do país de modo a faze-lo instrumento de seu progresso particular, isto é conquista a begemonia política necessária à conservação da hegemonia econômica já adquirida, ou separa-se, usando do direito de secessão”. (Monteiro Lobato, 1920) $^{1}$

Compreender o pensamento historiográfico como elemento importante do debate político de sua época é o ponto de partida desse trabalho. Retomo aqui algumas questões apresentadas em minha dissertação de mestrado ${ }^{2}$ sobre as disputas entre as cidades de São Paulo e do Rio de Janeiro, então capital federal, pelo lugar de "cabeça da nação brasileira”. O pressuposto é que a construção de uma memória histórica por ocasião da comemoração do centenário da independência, em 1922, teve como um de seus principais objetivos "redescobrir" o passado a partir de uma leitura que identificasse a história de São Paulo com a história do Brasil. Ao rejeitar o rótulo de "historiografia

\footnotetext{
${ }^{1}$ Monteiro Lobato, O direito de secessão, em Na antevéspera, São Paulo, Brasiliense, 1958, p. 209 (1 ed. 1920).

2 Marly S. Motta, A nação faz cem anos: a questão nacional no centenário da independência, Rio de Janeiro, Editora FGV, 1992.
} 
regional", essa produção visou a ocupar um espaço hegemônico na reflexão histórica sobre a formação da nação brasileira.

\section{Tempos de comemoração e de "salvação nacional”}

Monteiro Lobato, ao reivindicar para São Paulo "a preponderância no governo do país”, inserindo inclusive a hipótese de, em caso negativo, o estado buscar o caminho da "secessão", fazia coro com a intensa mobilização da " $m i$ norité agissante" ${ }^{3}$ que, no raiar da década de 1920, buscava um novo modelo para a nação brasileira. ${ }^{4}$ Além de Monteiro Lobato, intelectuais como Mario de Andrade, Oswald de Andrade, Oliveira Vianna, Tristão de Ataíde, Lima Barreto, Licínio Cardoso, dentre outros, ao mesmo tempo em que reconheciam os "graves" problemas do país, se declaravam empenhados na busca de novas alternativas para a "salvação nacional". Filiada a diversas concepções de brasilidade e de modernidade, essa intelectualidade partilhava a crença de que a construção de uma sociedade moderna dependia de um projeto de (re) construção da nação brasileira. ${ }^{5}$

$\mathrm{Na}$ qualidade de portadores dessa "missão salvacionista", os intelectuais se voltaram prioritariamente para a criação de um saber próprio sobre o país. Ocupando amplos espaços na imprensa, lócus privilegiado do debate

3 O termo é empregado por Eric Hobsbawm, em Nações e nacionalismo desde 1780, Rio de Janeiro, Paz e Terra, 1991, p. 21.

${ }^{4}$ Sobre nação e nacionalismo, ver, além da obra acima citada, Benedict Anderson, Nação $e$ consciência nacional, Rio de Janeiro, Ática, 1979; José Ramón Recalde, La construcción de las naciones, Madri, Siglo XXI, 1982. Da historiografia brasileira sobre o tema, destacaria, entre outros, Lucia Lippi Oliveira, A questão nacional na Primeira República, São Paulo, Brasiliense, 1990; Thomas E. Skidmore, Preto no branco: raça e nacionalidade no pensamento brasileiro, Rio de Janeiro, Paz e Terra, 1976; João Cruz Costa, Contribuição à história das idéias no Brasil, Rio de Janeiro, Civilização Brasileira, 1967; Renato Ortiz, Cultura brasileira e identidade nacional, São Paulo, Brasiliense, 1986. Gostaria ainda de citar as revistas Estudos Históricos, $\mathrm{n}^{\circ}$ 2, 1988 e Tempo Brasileiro, $\mathrm{n}^{\circ}$ 87, 1986, especialmente dedicadas à discussão da identidade nacional no Brasil.

5 Sobre as correntes de pensamento do início dos anos 1920, ver, além dos autores já citados, Eduardo Jardim de Moraes, A brasilidade modernista, Rio de Janeiro, Graal, 1978; e Roberto Romano, O conservadorismo romântico, São Paulo, Brasiliense, 1981. 
político-intelectual da época, envolveram-se em um processo de questionamento da identidade nacional e, em consequência, de elaboração de novos ideais e modelos, por vezes vagos e contraditórios, mas que se cristalizaram na medida em que se tornaram núcleos em torno dos quais se estruturaram as aspirações nacionais. Um bom exemplo, a meu ver, é o "dilema” proposto por Lobato: São Paulo é o progresso, e, por isso mesmo, deve servir de modelo para o país. Ou São Paulo se torna hegemônico, ou o país estaria condenado ao "atraso".

O centenário da independência, em 1922, foi avaliado como o momento ideal para acelerar o debate sobre a centenária nação brasileira, marcada, no entanto, pelo "atraso" em relação às "nações adiantadas" da Europa, conforme expressões usadas à época. Ao articular passado/presente/futuro, e mobilizar diferentes vertentes do movimento intelectual na busca de uma nação "brasileira e moderna”, o centenário não se reduziu à celebração de uma data memorável. Afinal, tem sido bem estudado o papel da constituição de uma memória comum no delicado processo de construção das nações. ${ }^{6}$ Lugar de memória da nação brasileira, depois de um difícil processo de consolidação no início da República, ${ }^{7}$ o 7 de setembro de 1922, ao ensejar o balanço obrigatório dos acontecimentos passados, a avaliação dos feitos presentes e a perspectiva de realizações futuras do país, promoveu a disputa entre diferentes projetos intelectuais que tinham como objetivo diagnosticar os "males" do país e, ao mesmo tempo, indicar a medicação necessária para a sua salvação. Amantes do campo ou da cidade, industrialistas ou ruralistas, tradicionalistas ou vanguardistas, as diferentes correntes de pensamento julgavam ser, cada uma a seu modo, porta-vozes do mundo moderno do pós-guerra.

No Brasil, a leitura dessa modernidade significou, antes de tudo, a busca por idéias singulares, não comprometidas com a "artificialidade" da importação

6 Ver, entre outros, Pierre Nora (dir.), Les lieux de mémoire, vol. I, La République, Paris, Gallimard, 1984; Eric J. Hobsbawm e Terence Ranger (org.), A invenção das tradições, Rio de Janeiro, Paz e Terra, 1984; José Murilo de Carvalho, A formação das almas: o imaginário da República no Brasil, São Paulo, Companhia das Letras, 1990; Manoel Luiz S. Guimarães, Nação e Civilização nos trópicos: o Instituto Histórico e Geográfico Brasileiro e o projeto de uma história nacional, Estudos Históricos, Rio de Janeiro, 1 (1): 5-27, 1988.

7 Ver Edgard Leite Ferreira Neto, O improviso da civilização: a nação republicana e a construção da ordem social no final do século XIX, Niterói, UFF, 1989 (dissert. Mestrado-mimeo). 
dos valores da Belle Epoque, considerada falida após a guerra de 1914. Claro que se deveria manter a Europa como referência, mas não como mera cópia, e sim por meio de uma integração seletiva e crítica das novas idéias que por lá circulavam. Embora correndo o risco de uma simplificação excessiva, ou mesmo de uma dicotomia por vezes artificial, pode-se dizer que duas grandes correntes marcaram o debate sobre a construção do Brasil moderno ao longo da década de 1920. Uma delas, ligada às idéias vanguardistas européias, rompia com os valores "clássicos", e buscava sintonizar a realidade nacional com o ritmo veloz e febril do novo mundo urbano e industrial. A outra, de caráter conservador, guiava-se pelos valores da natureza e do campo, pelo repúdio ao industrialismo e à modalidade da vida urbana, cosmopolita e litoralista. Ambas as correntes se uniam, no entanto, contra as pretensões da razão universal derrotada na guerra, e a favor da originalidade de cada nação. ${ }^{8}$

Pouco mencionado pela historiografia que tomou a questão nacional como objeto de estudo, um dos temas que mais se destacaram no debate sobre o Brasil moderno dos anos 1920 foi a busca de uma nova "cabeça" para a nação capaz de conduzi-la ao progresso e à modernidade. A imagem que Lobato construiu para São Paulo como a "locomotiva que arrastava rampa acima os 19 vagões irmãos", 9 apontava para um projeto que visava a substituir a cidade do Rio de Janeiro no lugar de centro produtor da identidade nacional.

\section{A “cabeça” da nação}

Liberta dos limites ditados por uma abordagem para a qual contavam apenas as mudanças de caráter econômico, a cidade deixou de ser simplesmente sinônimo de capitalismo, mercado, industrialização e urbanização. Vista como parte integrante de um mundo de símbolos entrelaçados, passou a ser entendida não apenas pelo que seu traçado e distribuição física permitiam ver, mas principalmente como símbolo de identidade de um espaço geográfico e

\footnotetext{
${ }^{8}$ Para uma análise mais detalhada dos diferentes projetos, ver Marly S. Motta, op. cit., cap. 1.

9 Cf. Monteiro Lobato, Mr. Slang e o Brasil e Problema vital, São Paulo, Brasiliense, 1958, p. 299 (1 ed. 1918).
} 
social, como forma, ao mesmo tempo, expressiva de conteúdo histórico e representativa de conceitos e valores. Representação visual de conteúdos históricos e culturais, a cidade, como nos ensina o belíssimo livro de Ítalo Calvino, é um discurso filosófico, literário e político. ${ }^{10}$

A matriz dessa concepção está em Lewis Mumford que, no seu The culture of cities, publicado em 1938, afirmava que a marca original da cidade havia sido a de um "ponto de encontro" que, além de satisfazer as necessidades imediatas do ser humano, teria gerado "instituições cívicas", como o teatro ou a universidade. ${ }^{11}$ A esta corrente analítica se filiou Giulio Argan - arquiteto, historiador da arte, prefeito comunista de Roma -, pioneiro no tratamento especial conferido ao surgimento das cidades-capitais, ${ }^{12}$ intimamente relacionado ao processo de estabelecimento das monarquias absolutistas européias no século XVII. Sedes da autoridade do Estado, dos órgãos do governo e da administração pública, comandando o movimento militar, controlando as principais rotas de comércio e a distribuição de recursos financeiros, monopolizando a arte, a cultura e o gosto, as cidades-capitais revelaram-se um objeto particularmente atraente para um tipo de abordagem que as analisa como o lugar da política e da cultura, como núcleo da sociabilidade intelectual e da produção simbólica, representando, cada uma à sua maneira, o papel de foco da civilização, núcleo da modernidade, teatro do poder e lugar de memória.

Símbolo da vontade de fazer da nação um só ser, a cidade-capital funda seu prestígio sobre a elaboração de uma memória, construída em mitos de fundação, monumentos e prédios, cerimônias e rituais, que a torna o retrato vivo da história nacional. Esse processo de construção da capital como centro formador do "espírito nacional" precisava contar com uma intelectualidade capaz de, como bem percebeu Angel Rama, organizar um discurso sobre a formação, composição e definição da nação. ${ }^{13}$ Por isso

\footnotetext{
10 Ver Ítalo Calvino, As cidades invisíveis, São Paulo, Companhia das Letras, 1990.

11 Lewis Mumford, A cidade na História: suas origens, transformações e perspectivas. São Paulo, Martins Fontes, 1982. Publicado pela primeira vez em 1961, este livro é uma versão ampliada e atualizada de A cultura das cidades, de 1938.

12 Ver Giulio Argan, L'Europe des capitales. Génève, Albert Skira, 1964.

13 Ver Angel Rama. A cidade das letras. São Paulo, Brasiliense, 1985, p. 93.
} 
mesmo, reconstruir o passado e escrever a biografia da nação seriam tarefas indispensáveis à constituição do Estado Nacional brasileiro ao longo do século XIX. Identificados com a política centralizadora, coube aos regressistas a iniciativa de criar instituições como o Instituto Histórico e Geográfico Brasileiro (IHGB) e o Arquivo Imperial. Seria na articulação das histórias regionais com a história nacional que mais nitidamente se observaria o florescer desse projeto claramente centralista e unitário. A partir do IHGB, no Rio de Janeiro, deveria ser - e efetivamente foi - empreendida a leitura das histórias regionais, desprovidas de suas potencialidades/especificidades políticas, evidenciando que era na capital que se operava o sistema de representações que definia as regiões. Daí a ênfase conferida ao debate regional no âmbito do IHGB, bem observada, aliás, por um contemporâneo: "Estranhas umas às outras, falta às nossas províncias a força do laço moral, o nexo da nacionalidade espontânea que poderia prender os habitadores dessa imensa peça."14

Não é difícil, pois, entender por que a transferência da capital de uma cidade para outra encerra, em si mesma, a aspiração de marcar um reinício, gerando uma intensa polarização entre a "nova" e a "antiga" capital, já que esta seria a expressão de uma tradição que se pretendia transformar em passado. A construção de São Petersburgo, iniciada em 1703 sob o patrocínio de Pedro, o Grande, é um bom exemplo. Voltada para o Báltico, base naval estratégica e importante centro de comércio, a cidade deveria ser para o Império Russo, em termos físicos e simbólicos, "uma janela para a Europa".15 Planejada por arquitetos europeus com um padrão arquitetônico de desenho retilíneo e geométrico, utilizado no Ocidente desde a Renascença, a nova capital, em contraposição à "velha" Moscou, berço das antigas tradições e guardiã da fé religiosa, deveria ser o lar da cultura secular e oficial. Prodigamente decorada e embelezada com fachadas de padrão ocidental, consideradas como "capas de civilização”, São Petersburgo foi, portanto, a expressão histórica de uma opção política e cultural que elegeu o modelo

\footnotetext{
14 Citado por Manoel L. S. Guimarães, op. cit., p. 14.

15 Marshall Bermann, Tudo que é sólido desmancha no ar: a aventura da modernidade. São Paulo, Companhia das Letras, 1986, p. 171.
} 
ocidental - racional, matemático e abstrato - como um ideal a ser atingido. Desse modo, a nova capital representou, no movimento pendular da sociedade russa, o momento em que a balança se inclinou favoravelmente à ocidentalização como a via capaz de transportá-la em direção ao futuro.

Embora a transferência efetiva da capital do Rio de Janeiro para São Paulo nunca tenha sido discutida institucionalmente, o que estava em jogo naquele momento de balanço do país era a afirmação de um novo lócus produtor da identidade nacional. Fundamental no processo de consolidação da hegemonia paulista (a "locomotiva") no conjunto nacional (os "vagões") seria a elaboração e a difusão de determinadas imagens, bem como a produção de certas representações, ${ }^{16}$ as quais, ao mesmo tempo em que deslegitimavam a "contemplativa" capital federal, qualificavam a "operosa" São Paulo como a nova "cabeça" da nação brasileira. A imagem da "cidade maravilhosa" à margem dos trilhos da modernidade, por onde correria a "locomotiva paulista", fixou-se indelevelmente na memória coletiva, e se incorporou definitivamente ao imaginário nacional.

\section{Tradição e vanguarda, teu nome é São Paulo.}

Arranha-céus/Fordes/Viadutos/um cheiro de café/no silêncio emoldurado.

(Oswald de Andrade)

Oriunda de diferentes regiões do país, uma parte expressiva da intelectualidade brasileira, partindo de modelos diferentes de nação, convergia na avaliação de que o Rio de Janeiro não representava mais as aspirações do Brasil moderno. Litoralista, desligada dos valores nacionais, passadista, dependente do Estado, a capital federal deveria ser substituída no seu tradicional papel de "cabeça da nação". A candidata a esse posto era São Paulo.

No entanto, o sucesso desse empreendimento dependeria da elaboração de uma argumentação sólida e abrangente, de caráter político, econômico,

16 Para o conceito de representações, ver Roger Chartier, A bistória cultural: entre práticas e representações. Rio de Janeiro, Bertrand Brasil, 1990. 
social e, sobretudo, histórico, capaz de garantir a São Paulo o lugar privilegiado de formador do "espírito nacional". Para tanto, seria indispensável que o "regionalismo paulista" fosse reconfigurado em favor de seu aspecto “nacionalista". A questão, no entanto, não era abandonar o regional, mas sim ressignificá-lo como nacional. Desse modo, a expansão para o Oeste, a lavoura cafeeira, a industrialização, deveriam se tornar temas predominantes na historiografia nacional, desde que claramente vinculados aos paulistas. Para firmar sua hegemonia, São Paulo precisava estabelecer uma clara identificação entre a sua própria história e a história do Brasil. ${ }^{17}$

A tese da predominância exclusiva dos interesses econômicos paulistas, traduzida na conquista da hegemonia política de São Paulo na federação brasileira ao longo da I República (1889-1930), tem sido contestada por vários estudos. ${ }^{18}$ As acirradas disputas políticas que marcaram o pleito presidencial de 1922 são um bom indicativo de que essa hegemonia ainda estava em jogo. ${ }^{19}$ A estratégia de mobilização do eleitorado encetada pela oposição ao mineiro Artur Bernardes, indicado pelo governo, atingiu mais fortemente a população da capital federal, cujos principais jornais acabaram se engajando a favor do fluminense Nilo Peçanha, candidato da Reação Republicana. A resposta do jornal Correio Paulistano contra a propaganda do candidato oposicionista viria em uma dupla direção. Primeiro, ao defender a predominância "natural” de São Paulo e Minas Gerais contra as denúncias de que significaria um "regionalismo nefando e grosseiro", o "imperialismo dos grandes estados": "[São Paulo] que contribui com a maior parte das rendas que sustenta a federação (...) e Minas, com os sete milhões de habitantes (...) não têm o direito de lembrar um nome para candidato à presidên-

17 Ver Monica Velloso, A brasilidade verde-amarela: nacionalismo e regionalismo paulista, Estudos Históricos, Rio de Janeiro, vol. 6, n. 11, 1993; e Maria de Lourdes Janotti, Historiografia, uma questão regional - São Paulo no período republicano, um exemplo, em Marcos A. da Silva (coord.), República em migalhas - bistória regional e local, S.Paulo, Marco Zero, 1990.

18 Ver, entre outros, Eduardo Kugelmas, Difícil hegemonia-um estudo sobre São Paulo na I República, São Paulo, USP, 1986 (tese de doutorado); Claudia Viscardi, O teatro das oligarquias: uma revisão da política do "café com leite", Belo Horizonte, C/Arte, 2001.

19 Ver Marieta de Moraes Ferreira, Em busca da Idade do Ouro 
cia da República?"20 Em seguida, ao investir contra o caráter "desordeiro e despolitizado" da população carioca, que havia vaiado estrondosamente Bernardes, e "trocado beijos" com Nilo Peçanha. O caráter racista fica evidente na observação do jornal de que não mereceria respeito o candidato que "andava aos beijos com a negrada". ${ }^{21}$ E concluía em outro artigo: "o Édipo de Piratininga aniquilará o monstro carioca". ${ }^{22}$

A tese da "inevitabilidade" da supremacia industrial de São Paulo também cedeu espaço a outras interpretações que apontam uma predominância duramente disputada com a cidade do Rio de Janeiro, então Distrito Federal, ao longo da década de 1920. O trabalho de Maria Antonieta Leopoldi questiona o alegado esvaziamento industrial carioca, ao destacar que a produção das indústrias da capital continuou a crescer nas três primeiras décadas do século $\mathrm{xx}$, embora em um ritmo mais lento que o do parque industrial de seu mais sério competidor. E mais: a comparação cidade-a-cidade era vantajosa para o Rio, já que o Censo de 1920 apontava que o valor da produção anual das indústrias cariocas era de 677 mil contos contra os 504 mil das indústrias paulistanas. ${ }^{23}$

Seria, no entanto, no campo das ideias, e, sobretudo, no terreno fluido da memória do passado, que se travariam os mais duros combates em favor da "metrópole bandeirante", não por acaso no momento em que, por força das comemorações do centenário da independência, buscava-se uma nova matriz capaz de conciliar os valores da modernidade dos "arranha-céus, fordes, viadutos", e da brasilidade do "cheiro do café". Ao combinar, em um mesmo espaço geográfico, os elementos dinâmicos da cidade e os valores tradicionais do campo, São Paulo se credenciaria a ser o novo coração do Brasil, simultaneamente "brasileiro e moderno".

20 Correio Paulistano, 21/10/1921, citado em Marly S. Motta, op. cit., p. 90.

21 Correio Paulistano, 9/11/1921, id. ibid., p. 90.

22 Correio Paulistano, 3/12/1921, id. ibid., p. 91.

23 Cf. Maria Antonieta Leopoldi, Crescimento industrial, políticas governamentais e organização da burguesia: Rio de Janeiro, de 1844 a 1914, Revista do Rio de Janeiro, Niterói, I (3):53-74, Mai-Ago, 1986. 


\section{“São Paulo se agita com a comemoração do centenário.”24}

“(...) por ela se fez a primeira conquista (...); por ela penetrou na América a civilização latina (...); por ela, os patriarcas da nossa emancipação politica conduziram dom Pedro I ao grito de 'Independência ou morte'; por ela, a escravidão voltou à liberdade; por ela, galvanizou o Brasil com os clarões de sua fé republicana (...).”

Em artigo publicado no Correio Paulistano de 8 de setembro de 1922 , Julio Prestes, futuro presidente do estado de São Paulo (1927-30), apresentava as razões pelas quais a capital paulistana deveria ser o centro das comemorações do centenário da independência. É fácil perceber que a construção dessa memória se assenta na confluência de elementos da geografia e da história, combinados de uma maneira especial para firmar a crença de que São Paulo era o "berço da nação".

Seguindo o roteiro traçado por Prestes, São Paulo foi apresentado como centro irradiador da "primeira conquista" do território da colônia (vila de São Vicente), e eixo de penetração da "civilização latina" no interior (as bandeiras). Afastados do litoral pela barreira da Serra do Mar, atraídos pelos rios que corriam para o "sertão", os bandeirantes de Piratininga, longe dos olhos da Coroa, puderam desenvolver, graças a essas peculiares circunstâncias geográficas, um ethos próprio, baseado em valores como "amor ao trabalho, à ordem, à disciplina, à determinação, à ação e ao pragmatismo”.

No entanto, essa invenção de tradição ${ }^{25}$ demandava um movimento mais amplo. Importante seria atualizar a imagem do bandeirante - "pioneiro, desbravador e empreendedor" -, restaurando uma linha de continuidade entre passado, presente e futuro. Herdeira desses valores, a liderança paulista estaria, mais do que qualquer outra, apta a guiar o país em busca de novos rumos que o levassem ao mundo moderno. Agora, o fundamental seria transitar da

\footnotetext{
24 Mario de Andrade, citado por Aracy Amaral, Artes plásticas na Semana de 1922, São Paulo, Editora Perspectiva, 1979, p. 65.

25 O termo está em Eric Hobsbawm e Terence Ranger (org.), A invenção das tradições, Rio de Janeiro, Paz e Terra, 1984.
} 
identidade particular (a "paulistanidade") para a identidade do todo (a nacionalidade). Ou seja, o caráter "bandeirante" deveria se entranhar na alma brasileira, e definir o até então fugidio "caráter nacional".

É sabido que o principal centro das comemorações do centenário seria a capital federal, onde se realizaria, entre outros eventos, a Exposição Universal do Centenário da Independência. ${ }^{26}$ São Paulo, no entanto, não ficaria para trás, e, como revela Mário de Andrade, a cidade "se agitava com a aproximação do Centenário”. Essa "agitação” refletia a compreensão de que esse seria um momento-chave para a afirmação da capital paulista diante da "outra" capital. A construção de um monumento dedicado aos bandeirantes foi sugerida pelo então presidente do estado, Washington Luiz, para o que constituiu uma comissão composta por Monteiro Lobato, Menotti Del Picchia e Oswald de Andrade.

Garantia de perenidade, promessa de eternidade, o monumento histórico trabalha pela continuidade de uma representação da história, e define uma ordem simbólica do passado. ${ }^{27}$ Não foi diferente com o Monumento das Bandeiras. O escultor Victor Brecheret, bastante admirado nos meios modernistas, foi encarregado de apresentar um projeto. No memorial que acompanhou a maquete, bem como nos elogios que a ela foram dedicados, é possível perceber que a força simbólica do Monumento residia em dois aspectos. Ao evocar "a vida, o martírio e a morte dos plasmadores da nossa nacionalidade", forjava a imagem dos "bravos paulistas como a expressão máxima do heroísmo e da glória da raça brasileira”. Ao ser concebido como um grande bloco reforçava o conceito simbólico das bandeiras como "uma força expandida em desvendar e integralizar o arcabouço geográfico da Pátria”. Acima de tudo, no entanto, o Monumento das Bandeiras era arte paulista com certeza, já que conjugava brasilidade e modernidade. De acordo com a avaliação de Menotti del Picchia, arte "tropical e indígena", "forte e espontânea", distante da "velharia e do arcaísmo" que costumavam enfeitar os salões da capital federal. ${ }^{28}$

\footnotetext{
26 Ver Marly S. Motta, op. cit., cap. 3.

27 Ver Jacques Le Goff, História e memória, Campinas, Unicamp, 1990.

28 Menotti Del Picchia, Monumento das Bandeiras, Correio Paulistano, 27/7/1920.
} 
Os bandeirantes eram apenas um dos trunfos que São Paulo possuía para se situar favoravelmente na disputa pela memória da nação centenária. Desde 1912, já estavam assegurados os recursos necessários à execução do Monumento do Ipiranga, destinado a fixar no bronze a lembrança do lugar onde o príncipe dom Pedro havia proferido o grito libertador, e outorgado ao país a sua maioridade política. Inaugurado em 7 de setembro, ainda que inacabado, o Monumento teria cumprido a sua missão, qual seja a de recuperar a "verdade histórica", colocando São Paulo no palco principal dos eventos comemorativos de 1922. Afinal, para os paulistas a data tinha o caráter duplo de uma celebração local e nacional.

Por meio dos fios da continuidade, São Paulo tecia a sua tradição. Inventou as bandeiras desbravadoras do território nacional, e os bandeirantes empreendedores e disciplinados, elevando-os à condição de eventos e personagens fundadores da história nacional. Transformou o riacho do Ipiranga em solo sagrado da pátria livre, e José Bonifácio no "patriarca da independência". Brasileiro nascido em Santos (São Paulo), Bonifácio foi elevado à condição de "mentor" do 7 de setembro, já que teria "conduzido" o jovem príncipe ao grito de "Independência ou morte". Se o fato de ser "paulista" contribuiu para seu ingresso no panteão dos "pais da pátria”, é certo que a defesa que Bonifácio fazia da ordem e da centralização, na direção oposta ao "idealismo liberal" vigente na Constituição republicana de 1891, agradava àqueles que, nos anos 1920, foram responsáveis pela formação de um pensamento autoritário no país. ${ }^{29}$

Essa invenção do passado era acompanhada, como de praxe, por apostas no presente e no futuro. Os "moços de São Paulo" - Mário e Oswald de Andrade, Tarsila do Amaral, entre outros - pretendiam transformar a comemoração do centenário em marco inaugural da hegemonia cultural de São Paulo. Foi Mário quem alertou: "A hegemonia artística da Corte [Rio de Janeiro] não existe mais. No comércio como no futebol, na riqueza como nas artes, São

29 Sobre José Bonifácio como "patriarca da independência”, ver Marly Motta, 1922, o Brasil faz cem anos: a herança portuguesa em questão. Texto apresentado no Colóquio Internacional A experiência da Primeira República: Portugal e Brasil, organizado pelo CEIS-20, da Universidade de Coimbra, e pelo CPDOC-FGV, realizado na Faculdade de Letras da Universidade de Coimbra e no Arquivo Distrital de Leiria, entre 5 e 7 de maio de 2010. 
Paulo caminha na frente". ${ }^{30} \mathrm{O}$ desafio à supremacia cultural até então irrefutável do Rio de Janeiro - ironicamente chamada de camelote - seria o elo que uniria variadas vertentes do modernismo paulista na montagem do evento conhecido como Semana de Arte Moderna, realizado no Teatro Municipal, entre 13 e 17 de fevereiro de 1922.

Diante do desafio de criar uma nação moderna, a "geração de 1922" investiu na produção de interpretações sobre o Brasil que inauguraram novos estilos de pensar o país, sua história, seus dilemas do presente e perspectivas de futuro. Com raízes fincadas nesse debate, a disputa pelo lugar de "nova cabeça da nação" implicou uma releitura do passado nacional, que visava a colocar São Paulo em posição privilegiada na qualidade de "modelo" para o Brasil que se preparava para comemorar seus cem anos de independência. A memória histórica então construída não apenas formou discípulos e seguidores na conformação de um pensamento historiográfico nacional, como foi elemento de consolidação da posição hegemônica de São Paulo no cenário nacional nas décadas seguintes.

\section{BIBLIOGRAFIA}

AMARAL, Aracy. Artes plásticas na Semana de 1922. São Paulo, Editora Perspectiva, 1979.

ANDERSON, Benedict. Nação e consciência nacional. Rio de Janeiro, Ática, 1979.

ARGAN, Giulio. L'Europe des capitales. Génève, Albert Skira, 1964.

BERMANN, Marshall. Tudo que é sólido desmancha no ar: a aventura da modernidade. São Paulo, Companhia das Letras, 1986.

CALVINO, Ítalo. As cidades invisíveis. São Paulo, Companhia das Letras, 1990.

CARVAlHO, José Murilo de. A formação das almas: o imaginário da República no Brasil. São Paulo, Companhia das Letras, 1990.

CHARTIER, Roger. A história cultural: entre práticas e representações. Rio de Janeiro, Bertrand Brasil, 1990.

COSTA, João Cruz. Contribuição à história das idéias no Brasil. Rio de Janeiro, Civilização Brasileira, 1967.

FERREIRA NETO, Edgard Leite. O improviso da civilização: a nação republicana e a construção da ordem social no final do século XIX, Niterói, UFF, 1989 (dissert. Mestrado-mimeo).

FERREIRA, Marieta de Moraes. Em busca da Idade do Ouro

30 Mario de Andrade, Notas de arte, A Gazeta, 13/2/1922. 
GUIMARÃES, Manoel Luiz S.. Nação e Civilização nos trópicos: o Instituto Histórico e Geográfico Brasileiro e o projeto de uma história nacional. Estudos Históricos. Rio de Janeiro, 1 (1): 5-27, 1988.

HOBSBAWM, Eric. Nações e nacionalismo desde 1780. Rio de Janeiro, Paz e Terra, 1991. \& RANGER, Terence (org.). A invenção das tradições. Rio de Janeiro, Paz e Terra, 1984.

JANOTTI, Maria de Lourdes. Historiografia, uma questão regional - São Paulo no período republicano, um exemplo. In: SILVA, Marcos A. da (coord.). República em migalbas - história regional e local. São Paulo, Marco Zero, 1990.

KUGELMAS, Eduardo. Dificil hegemonia - um estudo sobre São Paulo na I República. São Paulo, USP, 1986 (tese de doutorado).

LE GOFF, Jacques. História e memória, Campinas, Unicamp, 1990.

LEOPOLDI, Maria Antonieta. Crescimento industrial, políticas governamentais e organização da burguesia: Rio de Janeiro, de 1844 a 1914. Revista do Rio de Janeiro, Niterói, I (3):53-74, Mai-Ago, 1986.

LOBATO, Monteiro J.B.. O direito de secessão. In: Na antevéspera, São Paulo, Brasiliense, 1958, p. 209 (1 ed. 1920).

299 (1 ed. 1918).

MORAES, Eduardo Jardim de. A brasilidade modernista. Rio de Janeiro, Graal, 1978

MOTTA, Marly S.. A nação faz cem anos: a questão nacional no centenário da independência. Rio de Janeiro, Editora FGV, 1992.

MOTTA, Marly. 1922, o Brasil faz cem anos: a herança portuguesa em questão. Texto apresentado no Colóquio Internacional A experiência da Primeira República: Portugal e Brasil, organizado pelo CEIS-20, da Universidade de Coimbra, e pelo CPDOC-FGV, realizado na Faculdade de Letras da Universidade de Coimbra e no Arquivo Distrital de Leiria, entre 5 e 7 de maio de 2010.

MUMFORD, Lewis. A cidade na História: suas origens, transformações e perspectivas. São Paulo, Martins Fontes, 1982.

NORA, Pierre (dir.). Les lieux de mémoire. vol. I, La République, Paris, Gallimard, 1984.

OLIVEIRA, Lucia Lippi. A questão nacional na Primeira República. São Paulo, Brasiliense, 1990. ORTIZ, Renato. Cultura brasileira e identidade nacional. São Paulo, Brasiliense, 1986.

RAMA, Angel. A cidade das letras. São Paulo, Brasiliense, 1985.

RECALDE, José Ramón. La construcción de las naciones. Madri, Siglo XXI, 1982.

ROMANO, Roberto. O conservadorismo romântico. São Paulo, Brasiliense, 1981.

SKIDMORE, Thomas E.. Preto no branco: raça e nacionalidade no pensamento brasileiro. Rio de Janeiro, Paz e Terra, 1976.

VELLOSO, Monica. A brasilidade verde-amarela: nacionalismo e regionalismo paulista. Estudos Históricos. Rio de Janeiro, vol. 6, n. 11, 1993.

VISCARDI, Claudia. O teatro das oligarquias: uma revisão da politica do "café com leite". Belo Horizonte, C/Arte, 2001. 